THURSDAY, NOVEMBER Ir, 1880

\section{DR. SIEMENS'S NEW CURE FOR SMOKE}

7 HE growing obscurity which distinguishes the winter 1 atmosphere of London has disposed men to consider whether it is an indispensable evil connected with the use of coal in great centres of population, or whether means can be found of providing the warmth and comfort which the copious use of mineral fuel affords us without having to pay the penalty of dispensing with the solar ray, of finding ourselves and everything we touch covered with soot, and of occasionally having, even at midday, to grope our way with a feeling akin to suffocation.

I am decidedly of opinion that the evil is one which not only admits of remedy, but that its cure would result from a closer attention to the principles of economy in the use of fuel.

Until within recent years wasteful expenditure was the rule both in the application of fuel to our large manufacturing operations and for domestic purposes, but great strides have been made within the last twenty years to improve our mode of burning fuel both under our steam boilers and in the metallurgical furnace. The Regenerative Gas Furnace, which was the subject of Faraday's last discourse at the Royal Institution in 1862 has contributed its share to this result, combining as it does considerable economy, with the entire absence of smoke from the chimney.

Since by the employment of gaseous fuel results such as these are realised, there seems no d priori reason why analogous results should not attend its application on a smaller scale, even down to the means of heating our apartments, which, although a small application in each individual instance, amounts, in the aggregate, to the largest of all the uses of mineral fuel.

Gas-grates have been tried by individuals desiring progress, but I know several instances in which on account of the great comparative expense incurred, and objections raised to the smell, and dry heat, as it is called, in the room, the time-honoured smoky but cheerful coalfires were reinstated.

A gas-grate that was arranged in my billiard-room in the usual fashion, consisting of three air-gas-pipes with apertures distributed over the fire-grate, and covered with pumice-stone, presented certainly a cheerless appearance, and filled the room (notwithstanding a fair chimneydraught) with fumes, rendering the benefit of the fire a doubtful one. These fumes could not have passed into the room from the upper surface of the pumice-stone owing to its proximity to the chimney; but a little consideration made me come to the conclusion that these gases really proceeded from the ash-pan into the room. The products of combustion set up by the gas flames ascend no doubt so long as they are intensely hot, but in giving off their heat to the inert pumice-stone they rapidly cool, and being heavier than atmospheric air, descend through the grate between the lines of gas flames, and thus reach the apartment. Moreover the gas burnt towards the back of the fireplace takes scarcely any part in providing a red radiating surface in front of the grate, VoL. Xxirr.-No. 576 serving only to baffle the draught passing towards the chimney from the room.

The first condition to be realised in an efficient gasgrate consists in suppressing all gas orifices except immediately behind the bottom front bar, and in substituting for the grate a solid dead plate. Instead of using inert matter such as pumice-stone, I consider it far more economical and efficacious to transfer the heat of the gas flames to gas coke or anthracite, which when once heated helps the gas to increase and maintain a sufficient temperature for radiation through its own slow combustion. The gas should not be mixed in the pipe with atmospheric air to produce a Bunsen flame, as is frequently done, because by using the unmixed gas a rich flame is set up between the pieces of coke near the front of the grate, producing to the eye an appearance similar to a wellignited ordinary coal fire, and the hot carbonaceous matter through which it percolates ensures its entire combustion before reaching the chimney. Heat will however gradually accumulate towards the back of the fire, notwithstanding the suppression of the grate bars, and in order to obtain the utmost economy this heat should be utilised to increase the temperature of the gas flames and of the coke in front of the grate.

To accomplish this I have constructed a grate according to the annexed sketch. The iron dead plate $c$ is riveted to a stout copper plate $a$ facing the back of the fire-grate, and extending five inches both upwards and downwards from the point of junction. The dead plate $c$ stops short about an inch behind the bottom bar of the grate to make room for a half inch gas-pipe $f$, which is perforated with holes of about one twentieth of an inch in diameter placed zig-zag at distances of three-quarters of an inch along its upper surface. This pipe rests upon a lower plate $d$, which is bent downwards towards the back so as to provide a vertical and horizontal channel of about one inch in breadth between the two plates. A trap-door $e$, held up by a spring, is provided for the discharge of ashes falling into this channel. The vertical portion of this channel is occupied by a strip of sheet copper about four inches deep, bent in and out like a lady's frill and riveted to the copper back piece. Copper being an excellent conductor of heat, and this piece presenting (if not less than a quarter of an inch thick) a considerable sectional conductive area, transfers the heat from the back of the grate to the frill-work in the vertical channel. An air current is set up by this heat, which, in passing along the horizontal channel, impinges on the line of gas flames and greatly increases their brilliancy. So great is the heat imparted to the air by this simple arrangement that a piece of lead of about half a pound in weight introduced through the trap-door into this channel melted in five minutes, proving a temperature to exist exceeding $619^{\circ} \mathrm{F}$. or $326^{\circ} \mathrm{C}$. The abstraction of heat from the back has moreover the advantage of retarding the combustion of the coke there while promoting it at the front of the grate.

The sketch represents a fireplace at my office, in a room of 7,200 cubic feet capacity idcing the north. I always found it difficult during cold weather to keep this room at $60^{\circ} \mathrm{F}$. with a coal fire, but it has been easily maintained at that temperature since the grate has been altered to the gas-coke grate just described. 
This heating arrangement is not however essentially necessary; in several of the grates which I have altered for gas I have simply closed up the space below the bottom bar by means of a close-fitting ash-pan, and introduced the gaspipe behind the lower bar, an alteration which can be effected at very trifling expense, and presents the advantage of great cleanliness, the ashpan being withdrawn only at intervals of several days for emptying. The appearance of the fire however is in that case much less brilliant than when the hot-air arrangement is added.
In order to test the question of economy I have passed the gas consumed in the grate through a Parkinson's 10light dry gas-meter supplied to me by the Woolwich, Plumstead, and Charlton Consumer's Gas Company ; the coke used is also carefully weighed.

The result of one day's campaign of nine hours is a consumption of 62 cubic feet of gas and $22 \mathrm{lb}$. of coke (the coke remaining in the grate being in each case put to the debit of the following day). Taking the gas at the average London price of $3 s .6 d$. per 1000 cubic feet and the coke at $18 s$, a ton, the account stands thus for nine hours :-
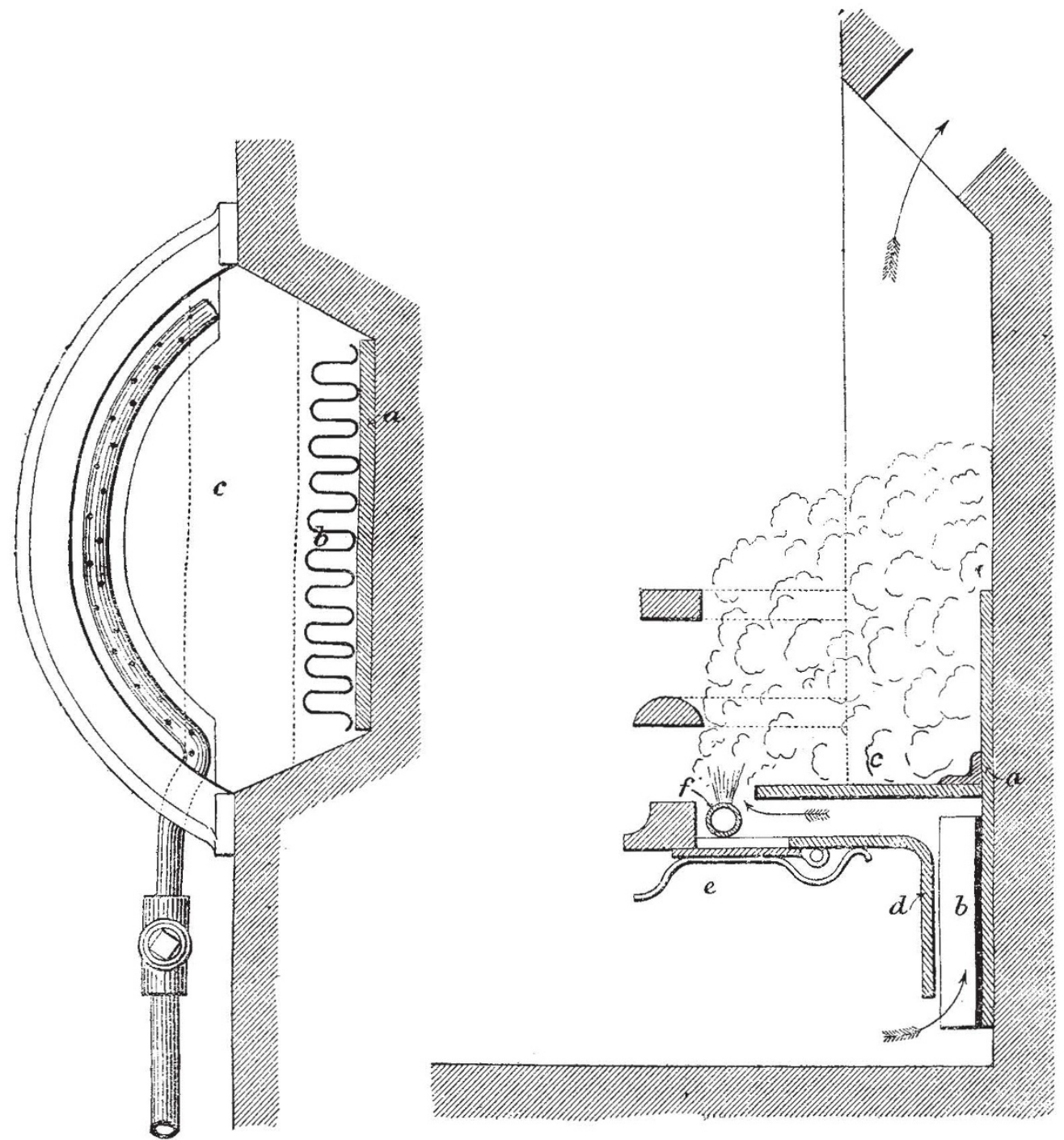

$a$, Copper plate $\frac{1}{4}$ inch thick and ro inches wide at back of grate; $b$, frill of copper $\frac{1}{16}$ inch thick; $c$, iron dead plate riveted to plate $a$; $d$, angle plate with trap-door $e$ for removing ashes; $f$, gas-pipe about $\frac{1}{2}$ inch diameter with holes $\frac{3}{4}$ inch apart.

62 cubic feet of gas at $3 s, 6 d$. per thousand $\quad \begin{array}{ll}d . & 2 \cdot 604\end{array}$

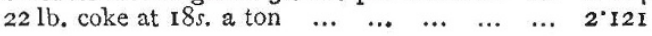

Total $\ldots \overline{4725}$

or at the rate of $0.524 d$. per hour. In its former condition as a coal-grate the consumption exceeded generally two and a balf large scuttles a day, weighing $19 \mathrm{lb}$. each, or $47 \mathrm{lb}$. of coal, which at $23 \mathrm{~s}$. a ton equals $57 \mathrm{~d}$. for nine hours, being $0.633 d$. per hour. This result shows that the co're-gas fire, as here described, is not only a warmer but a cheaper fire than its predecessor, with the advantages in its favour that it is thoroughly smokeless, that it can be put off or on at any moment (which in most cases means considerable economy), that it is lit without the trouble of laying the fire, as it is called, and keeps alight without requiring to be stirred.

It may appear strange at first that the use of the separated coke and gas to produce a given effect should be fully as cheap as using the raw material combining the two constituents, but the solution may be found in the 
circumstance that in the case of the coke-gas fire no heat flashes up the chimney, but is utilised entirely for raising the coke in front of the grate to the condition most favourable to radiation into the room.

I hold that it is almost barbarous to use raw coal for any purpose, and that the time will come when all our fuel will be separated into its two constituents before rcaching our factories or our domestic hearths. Such a measure would not only furnish us with the complete solution of the smoke question, but would be of great value also as a money saving. In conclusion I may observe that I have taken up this question without the idea of profit, and shall be happy to furnish builders and others desirous to introduce the grate here described with the necessary indications to insure success.

C. William Siemens

THE RUSSIAN IMPERIAL YACHT, "LIVADIA"

T N NATURE, vol. xxii. p. 270 , we gave an account of this remarkable ship, and stated that we should report the results of her trials to our readers We there said "it cannot be doubted that her speed will surpass I4 knots," and we pretty plainly intimated that it would, in our judgment, fall substantially short of 17 knots ; in point of fact it has fallen between these limits, and nearer the higher than the lower, the average mean speed at the measured distance being 15.864 knots. The details of the several runs, which have not previously been published in London, we believe, are as follows :-

\begin{tabular}{|c|c|c|c|c|c|c|}
\hline \multirow{2}{*}{\multicolumn{2}{|c|}{$\begin{array}{c}\text { No. of Run. } \\
I\end{array}$}} & \multicolumn{3}{|c|}{ Indicated FI.P. } & \multicolumn{2}{|c|}{ Speed in Knots. } \\
\hline & & $\cdots$ & 12,267 & $\ldots$ & $\cdots$ & 15.69 \\
\hline 2 & $\ldots$ & $\ldots$ & II, 704 & $\ldots$ & $\ldots$ & $\times 5.53$ \\
\hline 3 & $\ldots$ & $\ldots$ & I 2,387 & $\ldots$ & $\ldots$ & $15 \cdot 83$ \\
\hline 4 & $\cdots$ & $\ldots$ & I 2,437 & $\cdots$ & $\cdots$ & 15.65 \\
\hline 5 & $\ldots$ & $\ldots$ & 12,857 & $\cdot \ldots$ & $\ldots$ & 15.92 \\
\hline 6 & $\ldots$ & $\cdots$ & 12,472 & $\cdots$ & $\cdots$ & $15 \cdot 65$ \\
\hline & & erage & I2,354 & $\ldots$ & $\ldots$ & $15 \cdot 725$ \\
\hline
\end{tabular}

The trials of the Livadia were greatly hurried, the vessel going down the river on a Wednesday, making a preliminary run under steam on the following day, Thursday; on Friday she made a run at full speed for six hours, giving an average of 15 knots ; and on Saturday she made her measured mile trials. Those who understand the conditions under which these steam trials were made will see at once that it was not possible to obtain the best results with a ship thus put under steam day after day, her boiler tubes getting doubtless more or less foul, and her machinery also falling somewhat out of perfect condition, especially where there were three separate sets of engines to be cared for. The bottom was also foul from having been three months in the wet dock at Fairfield. The effect of haste in making the trials is visible in the variations of horse-power developed upon the runs, there being a difference of more than 1000 h.p. between the power developed, for example, on the second run as compared with that of the fifth. The speeds given above show less discrepancies than the horse-powers, but it can hardly be doubted that the Livadia as she is can be driven at over 16 knots under fair conditions, without any alteration whatever. It is, as has been said elsewhere, highly probable that some improvements might be made in the screw propellers, as it is not to be expected that the best conditions were secured at the first attempt. In fact we have evidence that the central screw was set at a pitch different from that of the sidescrews, and runs at a different speed; it now appears likely that the pitch should have been the same in all cases, and when the opportunity offers this change will probably be made, and the speed again taken. Other slight modifications will doubtless also be tried, and those of our own naval architects, who have well considered all the facts, have formed the opinion that if all minor causes of interference with the best performance are removed, a speed approaching 17 knots may be reached in the Livadia. It needs no words of ours to convince the scientific world that whether any great increase of speed be obtained with this vessel or not, the Russian Government has rendered a vast service to naval science by demonstrating on a large scale and in a public and unquestionable manner, the fact that a vessel whose breadth is enormous, and whose length is but one and a half times her breadth, may with no very inordinate expenditure of power be made to take a high place among the few fastest ships of the world.

But the interest in the Livadia, while it is greatest as regards her high-speed trials, by no means ends there. Her steaming performances with diminished steam power are also very interesting. In considering these the reader should remember that in this case as in all cases of fast ships going with reduced power and at reduced speed, the performances are subject to a double disadvantage: first the weight of the machinery carried is of course in excess of what is needed to produce the reduced power; and secondly, the friction and other losses are likewise in corresponding excess. For example, when the Livadia is stcaming say at $1 \mathrm{I}$ to $\mathrm{I} 2 \mathrm{knots}$, she is employing less power than any one of her three sets of engines produces; and if she had not to go beyond such a speed she might dispense with the other two sets of engines and boilers, and thus be relicved of nearly 1000 tons of weight, and of two-thirds of the frictional and other losses which she is obliged to undergo when steaming at II or I 2 knots with all her engines working at a reduced speed. Bearing these facts in mind, we may now state that the reduced steaming of the Livadia is reported officially to have given the following results :-

\begin{tabular}{|c|c|c|c|c|c|c|c|}
\hline \multicolumn{2}{|c|}{$\begin{array}{l}\text { Aggregate } \\
\text { Ind HA.P. }\end{array}$} & \multicolumn{2}{|c|}{ Specd. } & \multicolumn{3}{|c|}{ Win $\mathrm{t}}$. & \multirow{2}{*}{$\begin{array}{c}\text { Tide. } \\
\text { Slightly }\end{array}$} \\
\hline 2060 & $\ldots$ & IX & linots & $\ldots$ & With & $\ldots$ & \\
\hline $477 \circ$ & $\ldots$ & I3 & ," & $\ldots$ &, & $\ldots$ & \\
\hline 8940 & $\ldots$ & I5, & $:$ & $\ldots$ & Against & $\ldots$ & ghtly aga \\
\hline I0,037 & $\ldots$ & I $5 \frac{1}{4}$ & ", & $\ldots$ & , & $\ldots$ & Against \\
\hline
\end{tabular}

The indicated horse-powcrs above given were calculated from diagrams, and the specd was taken by log. The results were reported, we know, in perfect good faith, and are a correct indication, in the main, of the relation between power and speed in the Livadia with her present screws, \&c. They nevertheless appear to us to exhibit on the face of them some slight discrepancy, which is amply accounted for by the fact that the speeds were, as we have said, taken by the log, which does not admit of that minute accuracy which may and ought to characterise measured mile-trial results. The above figures are borne out by the sea-passages of the yacht. She steamed continuously in fair and moderate weather at an average speed of somewhat more than 12 knots with an average expenditure of about 4000 Ind. H.P.

With all the above facts and figures before us we see 